component of many integrated circuits, it provided the foundation for the 'computational plenty' that we now take for granted. This historical sweep certainly enlivens the section on unipolar devices, and the section on photonic devices is made similarly interesting with the recent social changes that have been brought about by solar power and lasers.

Sze provides a two-page introduction to each section. More intriguing is his short opening preamble in which he shows diagrammatically the relation between the principles of semiconductor devices, not only past and present, but

\section{Predictable plots}

John Lawton

A Critique for Ecology. By R. H. Peters. Cambridge University Press: 1991. Pp. 366. £45, $\$ 79.50$ (hbk); £17.95, $\$ 29.95(p b k)$.

CONSIDER the following propositions. The essence of science is prediction; the best way to make predictions is to regress variables one against the other; the more extravagant goals of science, for instance, that it should seek to understand what is going on, are unnecessary; ecology does not often make predictions; therefore most of contemporary ecology is not science. Briefly, that summarizes the central theme of this extraordinary book. In the author's own words: "Many ecologists .... have elected to build explanatory 'theories' which stress unity, reality, cause, and mechanism, but jettison predictive power. However, because a construct without predictive power tells us nothing, this choice represents a pathology whereby the trappings of theory beguile us away from predictive power." For predictive power, read graph.

It is a disappointing, uninspiring, negative book. That said, let me first add some qualifying comments, and say some positive things about it. Lest I be accused of simply defending my patch against devastating criticism, the work I have done comes in for relatively little adverse comment. Throughout my career, I have also done what Peters strongly advocates, namely mined the literature for data, and sought to establish (by drawing graphs) patterns in nature. (The difference is that I see the relationships as the beginning of understanding; for Peters they are an end in themselves.) I also share Peters' concern for the lack of apparent progress in solving some long-running problems in ecology, and have written at length ab- also for devices not yet realized. The bipolar transistor and MOSFET are seen to evolve through somewhat fantastic forms that may or may not work as devices. This is a small and imaginative addition to a weighty, informative reference volume. The book will be useful not only to technologists searching for their roots, but also to historians looking for the gritty realities of the semiconductor revolution.

Andrew Holmes-Siedle is owner of REM Instruments, 64A Acre End Street, Eynsham, Oxford OX8 1PD, UK, and a consultant to BNF-Fulmer Materials Centre, Wantage, UK.

out these. We ought to be soul-mates.

Instead, I find myself, more often than not, in fundamental disagreement with him.

Reading the book was like reading an essay written by a dreadfully earnest, but ill-informed, poorly read undergraduate, an essay needing copious red ink on every paragraph. A comprehensive response would require another book, so what follows is only a sample of my concerns.

Peters liberally criticizes several key ideas - for example, density-dependent versus density-independent 'regulation', stability and chaotic dynamics. They are variously dismissed as vague, undefined or useless 'mathematistry'. In fact he reveals several times that he does not understand these and related concepts and processes, or the mathematics that underpins them. I find it hard to believe that the book was properly refereed.

Analysis of causal links is dismissed as an "infinite research program" and a "singularly ineffective tool". What matters in solving pressing environmental problems are more empirical graphs. The absurdity of this proposition is made clear by two large environmental problems, one solved, the other on its way to being solved. The collapse of peregrine falcon populations throughout the world was reversed only by banning the pesticide DDT (dichlorodiphenyltrichloroethane) and other chlorinated hydrocarbons, and the case for doing so drew on brilliant environmental detective work that laid sufficiently bare the tortuous causal links between pesticides, eggshell thinning and the decline in peregrine numbers to convince politicians to act. Peters would have none of it. Or take the problem of acid deposition and forest decline in Europe. Here, the causal links are many, poorly understood and contentious, but they are becoming clearer. Peters is naive if he believes that graphs of depositions of $\mathrm{NO}_{x}$ and $\mathrm{SO}_{x}$ against tree deaths will, on their own, convince politicians that we must drastically curb emissions of these pollutants.
Before they act, politicians want mechanisms, because politicians are not stupid; indeed, they have been taught that although there is a good correlation between the population of storks in the Netherlands and the local birth rate, shooting storks is unlikely to slow human population growth. Understanding causality is not a luxury for effective environmental management, at least not in the world I live in.

Nowhere is the problem of inferring relationships from crude empiricism more clearly illustrated than by the problem of population densities for animals of different body sizes. Peters has made some useful empirical contributions to this field, and the graph relating body size to population density is referred to throughout the book as one of the most useful "predictive theories" (his words, not mine) in ecology. He admits that some species, particularly birds, do not conform well to the overall relationship, but fails to admit that the graph may hide more than it reveals.

For instance, because the graph is based on data drawn entirely from the literature, it under-represents rare species. Also, he explains the slope of the observed relationship (roughly -0.75 on a log-log plot) via per capita resource use and metabolic rates. But this presupposes that all populations are energylimited, and that equal amounts of energy are available for species of all body sizes. Neither seems likely.

In fact the relationship is poorly understood, and could be generated by several different mechanisms. The very thought is anathema to Peters; what matters is the graph and its 'predictive power'. But poorly understood relationships, based on possibly biased data, are not a wise basis for predicting anything. I prefer to understand what I am doing.

Most areas of science have good and bad parts, skilled and boring practitioners, useless and useful developments. Ecology is no different, and I suspect no worse than any other discipline (despite some contrived analyses by Peters to show otherwise). A Critique for Ecology paints a picture of a world that seems vaguely familiar, with which I can agree in part. On closer inspection it reveals a dismayingly patchy grasp of the subject, ruled by a rigid, not to say arcane, view of the philosophy of science, and adherence to the notion that real science is entirely about regressing one variable against another. If that were really the case, editions of Nature ought to consist of little more than a compilation of graphs.

John Lawton is at the NERC Centre for Population Biology, Imperial College at Silwood Park, Ascot, Berkshire SL5 7PY, UK. 